\title{
Summary of I 2th Asian Australasian Federation of Interventional and Therapeutic Neuroradiology (AAFITN 2016)
}

\author{
Prijo Sidipratomo', Cindy Sadikin²
}

Dear All,

We are very proud to announce that 12 th Asian Australasian Federation of Interventional and Therapeutic Neuroradiology (AAFITN 2016) has been successfully held on March 23rd - 25th, 2016 at Bali Nusa Dua Convention Center (BNDCC2) BALI, Indonesia in conjunctions with: 5th Annual Scientific Meeting Indonesian Society of Interventional Radiology, with the theme "Current Updates and Complication Management in Therapeutic Neuroradiology".

AAFITN was founded in 1994 by Professor Ling Feng. Previous congresses (Scientific conferences) were held by the following presidents: Ling Feng (1994 \& 1996 - Beijing), Akira Takahashi (2000 - Sendai, Japan), Dong I. Kim (2001 - Seoul, Korea), John Ching-Kwong Kwok (2002 - Hong Kong), Suthisak Suthipongchai (2004 - Bangkok, Thailand), Anil P. Karapurkar (2006 - Gore, India), Michael Mu Huo Teng (2008 - Taipei), Winston Chong (2010, Melbourne Australia), Shigeru Miyachi (2012), Pham

\footnotetext{
'Department of Radiology, Cipto Mangunkusumo Hospital, Jakarta, Indonesia

${ }^{2}$ Department of Radiology, Siloam Hospital, Surabaya, Indonesia Correspondence to: Cindy Sadikin, MD, Department of Radiology, Siloam Hospital, Surabaya. Raya Gubeng 70, Surabaya 60133, Indonesia.

Tel. 6231.5031333 Fax. 6231.5031533

E-mail: cindysadikin@yahoo.com.sg

This is an Open Access article distributed under the terms of the Creative Commons Attribution Non-Commercial License (http://creativecommons.org/licenses/by-nc/3.0) which permits unrestricted non-commercial use, distribution, and reproduction in any medium, provided the original work is properly cited.
}

Minh Thong - Vo Tan Son (2014, Danang Vietnam) and Prijo Sidipratomo (2016, Bali, INDONESIA).

We are delightful to continue AAFITN visionary spirit to promote the major breakthrough and developments in the field of interventional and therapeutic neuroradiology, from clinical practice to research and technology within Asian-Australasian regions. This meeting became unique for its more interactive method for not only one way lecture but giving more opportunity for participants to be actively involved in case discussion using electronic voting system.

Altogether, there were 32 Exhibition, which as well involved in 8 Scientific Highlight, and 324 Participants from 22 Countries from: Korea, Japan, Taiwan, China,

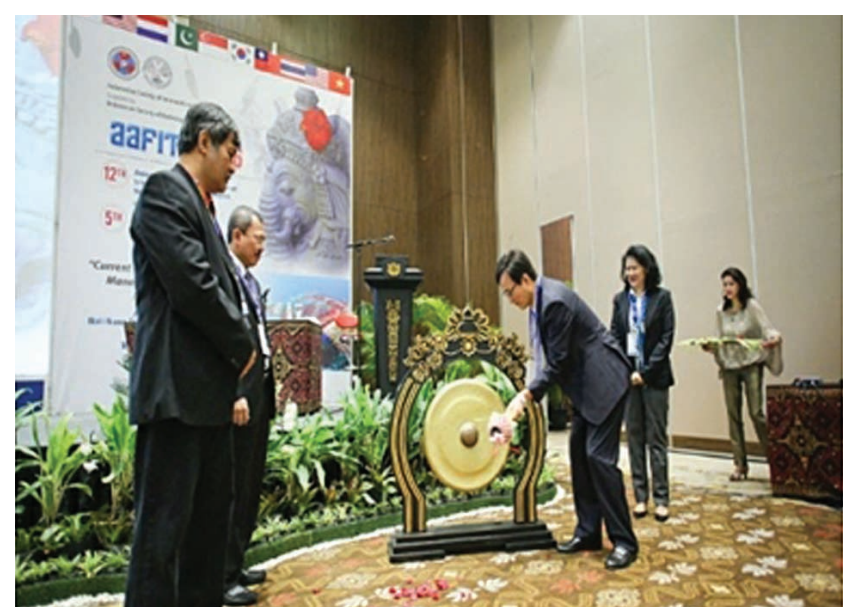

Fig. 1. AAFITN 2016 opening ceremony by Prof. Dae Chul Suh as the President of AAFITN, accompanied by Prof. Sirintara Pongpech as the President of WFITN, Terawan Putranto, MD as the President of Indonesian Radiology Society and Prijo Sidipratomo, MD as Chairman of AAFITN 2016 in Bali Nusa Dua Convention Center, INDONESIA. 
Vietnam, Malaysia, Thailand, Singapore, Australia, Austria, The Netherlands, France, Canada, USA, Germany, Pakistan, India, Bangladesh and certainly our growing Indonesian Society members.

There were 84 Poster Presenters and 37 Oral Presenters. With the total 121 free paper abstracts, we had received the huge response for young investigators in promoting the neuro-intervention therapy, coming from all countries, who's eager to communicate their results of studies, researches and experience, which are very prideful to all of us. To continue the tradition of AAFITN, the Organizing Committee therefore decided to facilitate the accepted abstract of Free Paper contributors to join the stand online-only supplements to the Journal Interventional Neuroradiology.

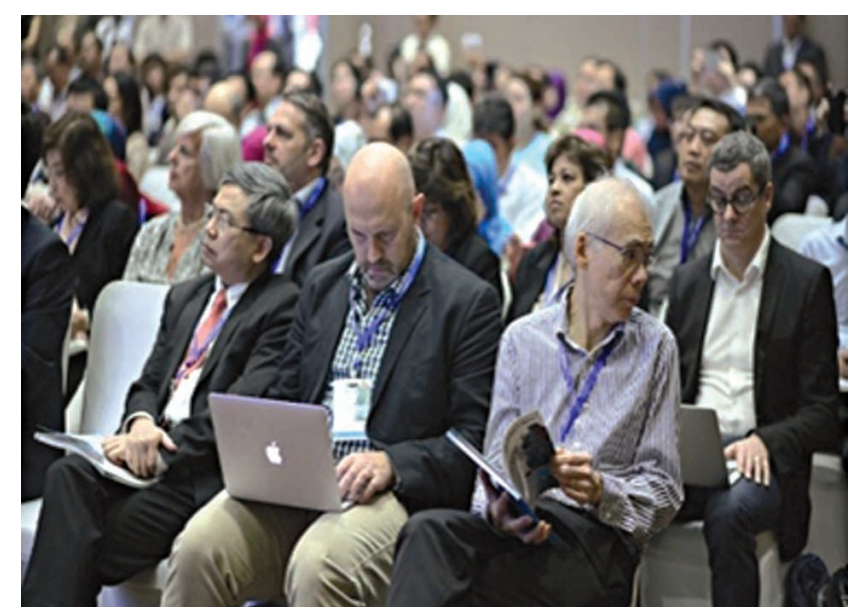

Fig. 2. Participant enthusiasm during lectures. Prof. Chistrophe Cognard, Prof. Pham Minh Thong, Prof. Winston Chong and Dr. Josephine Subramanian were also seen in the crowd.
We had couple of social events: Faculty Pirate Cruise Dinner and Cultural Fest that have bonded us together and became a wonderful memorable moment for us.

The next AAFITN will be held in Malaysia on March 28 th -31 st 2018 . We believe it will be a great and successful congress.

So see you all in Malaysia.

\section{Chairman}

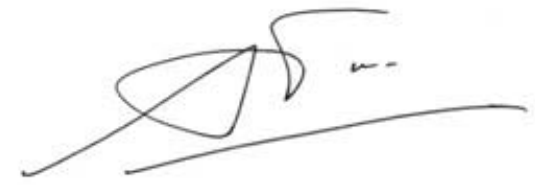

Prijo Sidipratomo MD

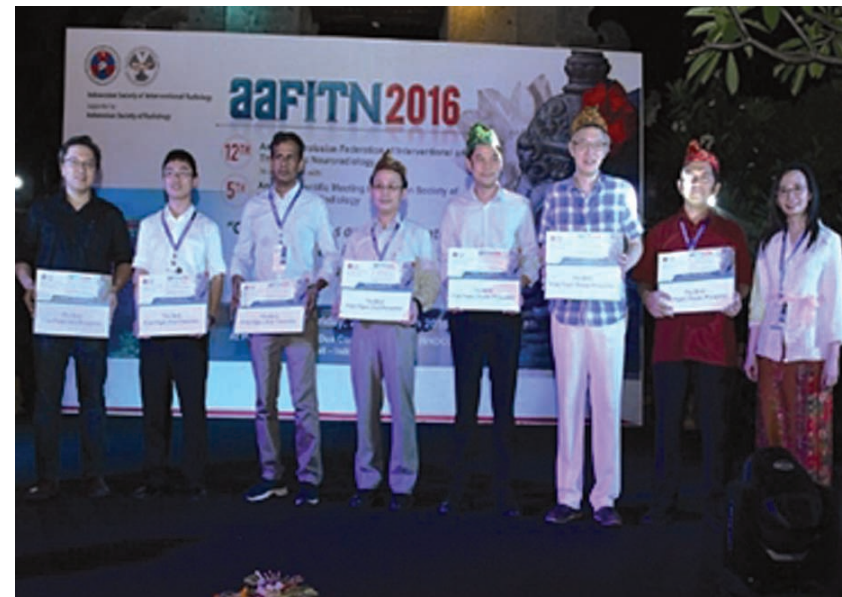

Fig. 4. Winners from best Oral and Poster Presentation in AAFITN 2016 with Scientific Committee Coordinator Cindy Sadikin, MD
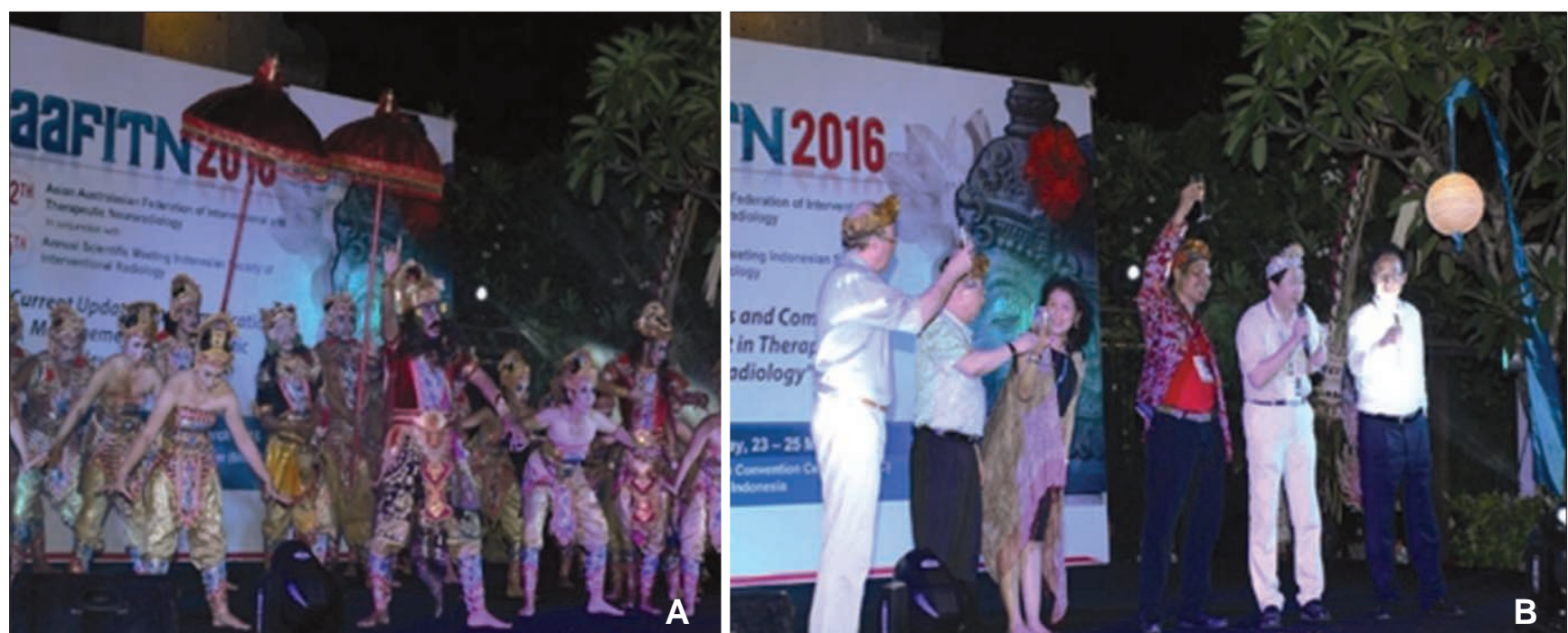

Fig. 3A and 3B. Memorable moments from Cultural Fest Dinner during AAFITN 2016 with traditional entertainment and culinary, bounded colleagues and new friends from all over the country 